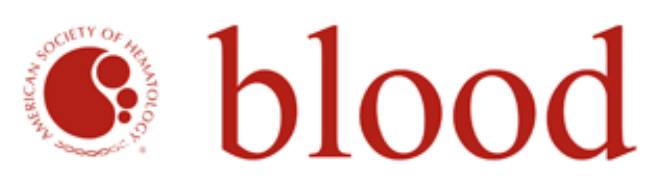

2011 118: 6141-6152

doi:10.1182/blood-2011-08-374728 originally published online October 13, 2011

\title{
CD73-generated extracellular adenosine in chronic lymphocytic leukemia creates local conditions counteracting drug-induced cell death
}

Sara Serra, Alberto L. Horenstein, Tiziana Vaisitti, Davide Brusa, Davide Rossi, Luca Laurenti, Giovanni D'Arena, Marta Coscia, Claudio Tripodo, Giorgio Inghirami, Simon C. Robson, Gianluca Gaidano, Fabio Malavasi and Silvia Deaglio

Updated information and services can be found at:

http://www.bloodjournal.org/content/118/23/6141.full.html

Articles on similar topics can be found in the following Blood collections

Immunobiology (5218 articles)

Lymphoid Neoplasia (1827 articles)

Information about reproducing this article in parts or in its entirety may be found online at:

http://www.bloodjournal.org/site/misc/rights.xhtml\#repub_requests

Information about ordering reprints may be found online at:

http://www.bloodjournal.org/site/misc/rights.xhtml\#reprints

Information about subscriptions and ASH membership may be found online at:

http://www.bloodjournal.org/site/subscriptions/index.xhtml

Blood (print ISSN 0006-4971, online ISSN 1528-0020), is published weekly by the American Society of Hematology, 2021 L St, NW, Suite 900, Washington DC 20036.

Copyright 2011 by The American Society of Hematology; all rights reserved. 


\title{
CD73-generated extracellular adenosine in chronic lymphocytic leukemia creates local conditions counteracting drug-induced cell death
}

\author{
Sara Serra, ${ }^{1}$ Alberto L. Horenstein, ${ }^{2}$ Tiziana Vaisitti, ${ }^{1}$ Davide Brusa, ${ }^{1}$ Davide Rossi, ${ }^{3}$ Luca Laurenti, ${ }^{4}$ Giovanni D'Arena,${ }^{5}$ \\ Marta Coscia, ${ }^{6}$ Claudio Tripodo, ${ }^{7}$ Giorgio Inghirami, ${ }^{8}$ Simon C. Robson, ${ }^{9}$ Gianluca Gaidano, ${ }^{3}$ Fabio Malavasi, ${ }^{2}$ and \\ Silvia Deaglio ${ }^{1}$ \\ ${ }^{1}$ Human Genetics Foundation (HuGeF) and 'Laboratory of Immunogenetics, Department of Genetics, Biology, and Biochemistry, University of Turin, Turin, Italy; \\ ${ }^{3}$ Division of Hematology, Department of Clinical and Experimental Medicine and Interdisciplinary Research Center of Autoimmune Diseases, Amedeo Avogadro \\ University of Eastern Piedmont, Novara, Italy; ${ }^{4}$ Institute of Hematology, Catholic University of the Sacred Heart, Rome, Italy; ${ }^{5}$ stituto di Ricovero e Cura a \\ Carattere Scientifico "Casa Sollievo della Sofferenza" Hospital, San Giovanni Rotondo, Foggia, Italy; ${ }^{\circ D i v i s i o n ~ o f ~ H e m a t o l o g y, ~ L a b o r a t o r y ~ o f ~ H e m a t o l o g y ~}$ \\ Oncology, Center of Experimental Research and Clinical Studies, San Giovanni Battista University Hospital, Turin, Italy; ${ }^{7}$ Tumor Immunology Unit, Department \\ of Health Science, Human Pathology Section, University of Palermo, Palermo, Italy; ${ }^{8}$ Department of Pathology, Center for Experimental Research and Medical \\ Studies, Turin, Italy; and 'Department of Medicine, Beth Israel Deaconess Medical Center, Harvard Medical School, Boston, MA
}

\begin{abstract}
Extracellular adenosine (ADO), generated from ATP or ADP through the concerted action of the ectoenzymes CD39 and CD73, elicits autocrine and paracrine effects mediated by type 1 purinergic receptors. We have tested whether the expression of CD39 and CD73 by chronic lymphocytic leukemia (CLL) cells activates an adenosinergic axis affecting growth and survival. By immunohistochemistry, CD39 is widely expressed in CLL lymph nodes, whereas CD73 is re-
\end{abstract}

stricted to proliferation centers. CD73 expression is highest on $\mathrm{Ki}-67^{+} \mathrm{CLL}$ cells, adjacent to $\mathrm{T}$ lymphocytes, and is further localized to perivascular areas. $\mathrm{CD} 39^{+} /$ $\mathrm{CD}^{+}{ }^{+} \mathrm{CLL}$ cells generate ADO from ADP in a time- and concentration-dependent manner. In peripheral blood, CD73 expression occurs in $97 / 299(32 \%)$ CLL patients and pairs with CD38 and ZAP-70 expression. CD73-generated extracellular ADO activates type 1 purinergic A2A receptors that are constitutively expressed by CLL cells and that are further elevated in proliferating neoplastic cells. Activation of the ADO receptors increases cytoplasmic cAMP levels, inhibiting chemotaxis and limiting spontaneous drug-induced apoptosis of CLL cells. These data are consistent with the existence of an autocrine adenosinergic loop, and support engraftment of leukemic cells in growth-favorable niches, while simultaneously protecting from the action of chemotherapeutic agents. (Blood. 2011;118(23):6141-6152)

\section{Introduction}

Chronic lymphocytic leukemia (CLL) was traditionally considered an accumulative disease of immune incompetent monoclonal B lymphocytes expressing CD5 and CD23. ${ }^{1}$ Recent data, however, have demonstrated that up to $1 \%$ of the leukemic clone renovates daily, implying that a sizeable fraction of neoplastic cells must die each day in patients with indolent clinical disease. ${ }^{2,3}$ The current most credited view identifies specific lymph node (LN) and bone marrow (BM) niches as sites of cellular turnover in CLL. ${ }^{4}$ Here, anatomically defined structures termed proliferation centers are marked by the presence of $\mathrm{Ki}-67^{+}$proliferating CLL cells that interact with $\mathrm{CD}^{+} \mathrm{T}$ cells and with the heterogeneous stromal components. ${ }^{5,6}$ In addition to cell-cell contacts, soluble mediators also drive CLL survival and proliferation, as inferred by studies using autologous blood serum or conditioned medium of stromal cells. ${ }^{7,8}$

Extracellular nucleotides and nucleosides, such as adenosine triphosphate (ATP) and adenosine (ADO), respectively, may participate in creating favorable conditions that promote tumor growth and survival, while suppressing the host immune responses. ${ }^{9}$ Extracellular ATP binds multiple type-2 purinergic and pyrimidinergic ( $\mathrm{P} 2 \mathrm{Y}$ and $\mathrm{P} 2 \mathrm{X}$ ) receptors, influencing cellular metabolism, migration, proliferation, and apoptosis (reviewed in Burnstock ${ }^{10}$ and Burnstock and Verkhratsky ${ }^{11}$ ). Nucleotides also may serve as substrates for the ectonucleotidases that are surface molecules with catalytic sites located in the extracellular compartment. As examples, CD39 (ENTPD1, EC 3.6.1.5) hydrolyses ATP or ADP to AMP; AMP is then rapidly degraded to ADO by soluble or membrane-bound CD73 (5'-nucleotidase, EC 3.1.3.5). ${ }^{12}$ ADO may be taken up by cells to reconstitute the nucleotide pool, or it may elicit potent immunosuppressive and anti-inflammatory responses, mediated through the interaction with a specific family of type 1 purinergic $\mathrm{G}$ protein-coupled receptors (A1, A2A, A2B, and A3). ${ }^{13,14} \mathrm{ADO}$ production is an integral component of the suppressive machinery of regulatory $\mathrm{T}$ cells, blunting effector $\mathrm{T}$-cell proliferation and secretion of T-helper 1-type cytokines. ${ }^{15,16}$ Less known are the effects mediated by the adenosinergic axis through autocrine mechanisms. ${ }^{17}$

Several lines of evidence suggest that the tumor microenvironment is marked by increased turnover of extracellular nucleotides ${ }^{18}$ and nucleosides, ${ }^{19}$ as well as by up-regulation of ectoenzymes that dismantle them. Elevated expression and activity of CD73 have been reported in several types of solid tumors ${ }^{20}$ and in certain types of leukemia, ${ }^{21}$ suggesting that it may be beneficial to the survival of tumor cells and could promote metastatic spread. ${ }^{22}$ These effects
Submitted August 19, 2011; accepted October 6, 2011. Prepublished online as Blood First Edition paper, October 13, 2011; DOI 10.1182/blood-2011-08-374728.

The online version of the article contains a data supplement.
The publication costs of this article were defrayed in part by page charge payment. Therefore, and solely to indicate this fact, this article is hereby marked "advertisement" in accordance with 18 USC section 1734.

(C) 2011 by The American Society of Hematology 
might be achieved through multiple processes, involving ADOmediated autocrine and paracrine mechanisms. ${ }^{23}$

On these grounds, we have investigated expression of CD39 and CD73 by CLL cells and evaluated the functional significance of the autocrine ADO production supporting the survival of the leukemic cells and their expansion.

\section{Methods}

\section{Patient samples}

We obtained 299 CLL blood samples in accordance with Institutional Guidelines at the University of Turin and Declaration of Helsinki. Analyses are detailed in supplemental Methods (available on the Blood Web site; see the Supplemental Materials link at the top of the online article).

Cells were cultured in AIM V serum-free medium (Invitrogen). Activation was induced using CpG ODN2006K ( $1 \mu \mathrm{g} / \mathrm{mL}$; TibMolBiol) and recombinant human IL-2 (100 IU/mL; R\&D Systems).

\section{Reagents}

ADP, AMP, ADO, HPLC-grade reagents (methanol and acetonitrile), etoposide, fludarabine, CGS21680 (A2A receptor agonist), SCH58261 (A2A receptor antagonist), $\alpha, \beta$-methylene-ADP (APCP), and forskolin (adenylate cyclase activator) were from Sigma-Aldrich.

\section{Immunohistochemistry and immunofluorescence microscopy}

Formalin-fixed, paraffin-embedded sections of LNs infiltrated by CLL cells were from the departments of pathology of the universities of Turin, Eastern Piedmont, and Palermo, Italy. Sections from 27 CLL cases were deparaffinized, and endogenous peroxidase activity was blocked. Epitope retrieval was performed in $0.01 \mathrm{M}$ citrate buffer, $\mathrm{pH} 6.0$ (for 40 minutes at $98^{\circ} \mathrm{C}$ ). Antibodies used are detailed in supplemental Methods. Samples were counterstained with 4,6-diamidino-2-phenylindole and mounted in SlowFade Gold reagent (both from Invitrogen). Slides were analyzed using a TCS SP5 laser scanning confocal microscope with 4 lasers (Leica Microsystems); images were acquired with LAS AF Version Lite 2.4 software (Leica Microsystems) and processed with Photoshop (Adobe Systems). Pixel intensity analyses were performed using ImageJ (National Institutes of Health; http://rsbweb.nih.gov/ij/) and LAS Application Suite Version 3.8 software (Leica Microsystems).

\section{FACS analyses}

Abs used are detailed in supplemental Methods. Data were acquired using a FACSCanto II cytofluorimeter (BD Biosciences) and processed with FlowJo Version 9.01 software (TreeStar).

\section{RNA extraction and quantitative RT-PCR}

RNA was extracted using RNeasy Plus Mini kit (QIAGEN) and converted to cDNA using the High Capacity cDNA Reverse Transcription kit (Applied Biosystems). Quantitative real-time PCR (RT-PCR) was performed using the 7900 HT Fast Real Time PCR system (SDS2.3 software) using commercial primers (TaqMan Gene Expression Assays; Applied Biosystems). The comparative CT method was used to calculate the expression relative to the endogenous control. ${ }^{24}$

\section{HPLC measurement of adenosine}

Purified CLL cells were incubated (for 60 minutes at $37^{\circ} \mathrm{C}$ ) in AIM V medium with $100 \mu \mathrm{M}$ ADP. Supernatant preparation and HPLC separation procedures are detailed in supplemental Methods. All concentrations are expressed as micromoles per hour per $10^{6}$ cells.

\section{Intracellular cAMP measurements}

Resting or activated purified CLL cells $\left(2 \times 10^{5} /\right.$ well) were incubated (for 30 minutes at $\left.37^{\circ} \mathrm{C}\right)$ with $\mathrm{CGS} 21680(1-10 \mu \mathrm{M})$ or forskolin $(10 \mu \mathrm{M})$. Intracellular cAMP was measured using an enzyme immunoassay (GE Healthcare).

\section{Chemotaxis assay}

Chemotaxis assays to CXCL12 (60 ng/106 cells/well; R\&D Systems) were performed in the Boyden chamber, as described previously. ${ }^{25}$ When indicated, CLL cells $\left(10^{6} /\right.$ well) were preincubated with CGS21680 (1-10 $\mu \mathrm{M}$; for 30 minutes at $\left.37^{\circ} \mathrm{C}\right)$ or APCP $\left(10-3 \mu \mathrm{M}, 60\right.$ minutes, $\left.37^{\circ} \mathrm{C}\right)$ before washing and plating in the upper part of the chamber. ADO was left for the whole length of the assay (4 hours). The migration index (MI) was calculated as follows: number of $\mathrm{CD} 19^{+} / \mathrm{CD}^{+}$cells transmigrating in presence of $\mathrm{CXCL} 12 /$ number of $\mathrm{CD} 19^{+} / \mathrm{CD}^{+}$cells transmigrated in absence of the chemokine. ${ }^{25}$ The MI obtained in the presence of CXCL12 alone was considered 1, and a fold difference was calculated for the different treatments. Chemotaxis was measured in 2 separate wells for each condition.

\section{Apoptosis assay}

Freshly purified CLL cells were pre-treated with CGS21680, SCH58261 $\left(1-10 \mu \mathrm{M}\right.$, for 30 minutes at $\left.37^{\circ} \mathrm{C}\right)$ and $\mathrm{APCP}(3-10 \mu \mathrm{M}$ for 60 minutes at $\left.37^{\circ} \mathrm{C}\right)$. Cells were plated $\left(3 \times 10^{5} /\right.$ well $)$ in AIM $\mathrm{V}$ medium, adding extracellular ADO $(50 \mu \mathrm{M})$. Apoptosis was induced with etoposide $(50 \mu \mathrm{M}$, for 16 hours at $\left.37^{\circ} \mathrm{C}\right)$ or fludarabine $\left(5 \mu \mathrm{M}\right.$, for $48-72$ hours at $\left.37^{\circ} \mathrm{C}\right)$ and measured with an annexin V-FITC Apoptosis kit (Invitrogen).

\section{Western blot analysis}

Whole cell lysates were resolved by SDS-PAGE and transferred to polyvinylidene difluoride membranes (Millipore). ${ }^{25}$ Abs used are detailed in supplemental Methods. Densitometric analyses were performed using the ImageQuant TL Version 1 software (GE Healthcare).

\section{Statistical analyses}

Continuous variables were compared by Student $t$, Mann-Whitney $U$, or Wilcoxon signed rank tests. Correlation between continuous variables was assessed using Pearson correlation coefficients. Data were analyzed with SPSS Version 18.0 (SPSS) and Prism software Version 5.0 (GraphPad Software).

\section{Results}

\section{CD73 is expressed in proliferation centers and in perivascular areas}

CD39 and CD73 are members of a pathway of ectoenzymes that participate in a cascade leading to ADO synthesis. They are coexpressed on many cells, including regulatory $\mathrm{T}$ cells, and by the vasculature within solid tumors. The adenosinergic axis acts in a local microenvironment, where extracellular levels of ATP and ADP might be increased as a consequence of an accelerated cellular turnover. CD39 and CD73 expression patterns were investigated by immunohistochemistry in LN sections from CLL patients. The samples $(n=27)$ displayed an almost complete effacement of the normal LN architecture by CLL cells and evidence of morphologically distinct pseudofollicles, comprising areas rich in prolymphocytes and paraimmunoblasts. CD39 was scored positive in all cases, with different intensities across samples. Besides leukemic lymphocytes, the stromal meshwork also was intensely CD39+ (Figure 1A-B). CD73 expression was scored positive in 10/27 cases $(37 \%)$. Expression was significantly higher in the paler areas 
Figure 1. Immunohistochemistry analysis of CD39 and CD73 expression. (A-B) Anti-CD39 immunostaining of 2 representative $L N$ tissue sections using anti-mouse HRP-conjugated secondary $\mathrm{Ab}$ and 3,3'-diaminobenzidine (brown signal). CLL lymphocytes stain uniformly positive, even if with different intensity levels. Original magnification $\times 20$. (C-D) Anti-CD73 immunostaining of a representative $\mathrm{LN}$ from a CLL patient using anti-rabbit HRP-conjugated secondary $\mathrm{Ab}$ and 3,3'-diaminobenzidine (brown signal). Low magnification shows $\mathrm{CD} 73$ expression around the paler areas corresponding to the proliferation centers. Original magnification $\times 4(\mathrm{C})$ and $\times 10$ (D). (E-F) Higher magnification shows that $C D 73^{+}$ cells have a prolymphocytic morphology and that perivascular areas are enriched in $\mathrm{CD}_{73}{ }^{+}$cells. Endothelial cells are $\mathrm{CD}_{73}{ }^{+}$, as expected. Original magnification $\times 40$. (G-H) Quantification of the percentage of $\mathrm{CD}^{2} 3^{+}$areas (brown pixels) in at least 15 different $\times 20$ fields obtained from 5 independent sections depicting proliferation centers (PC), vessels, or the rest of the section (other). Images were analyzed using a DMI 3000 B optical microscope (Leica Microsystems), equipped with a DCF $310 \mathrm{FX}$ digital camera and LAS Version 3.8 software.
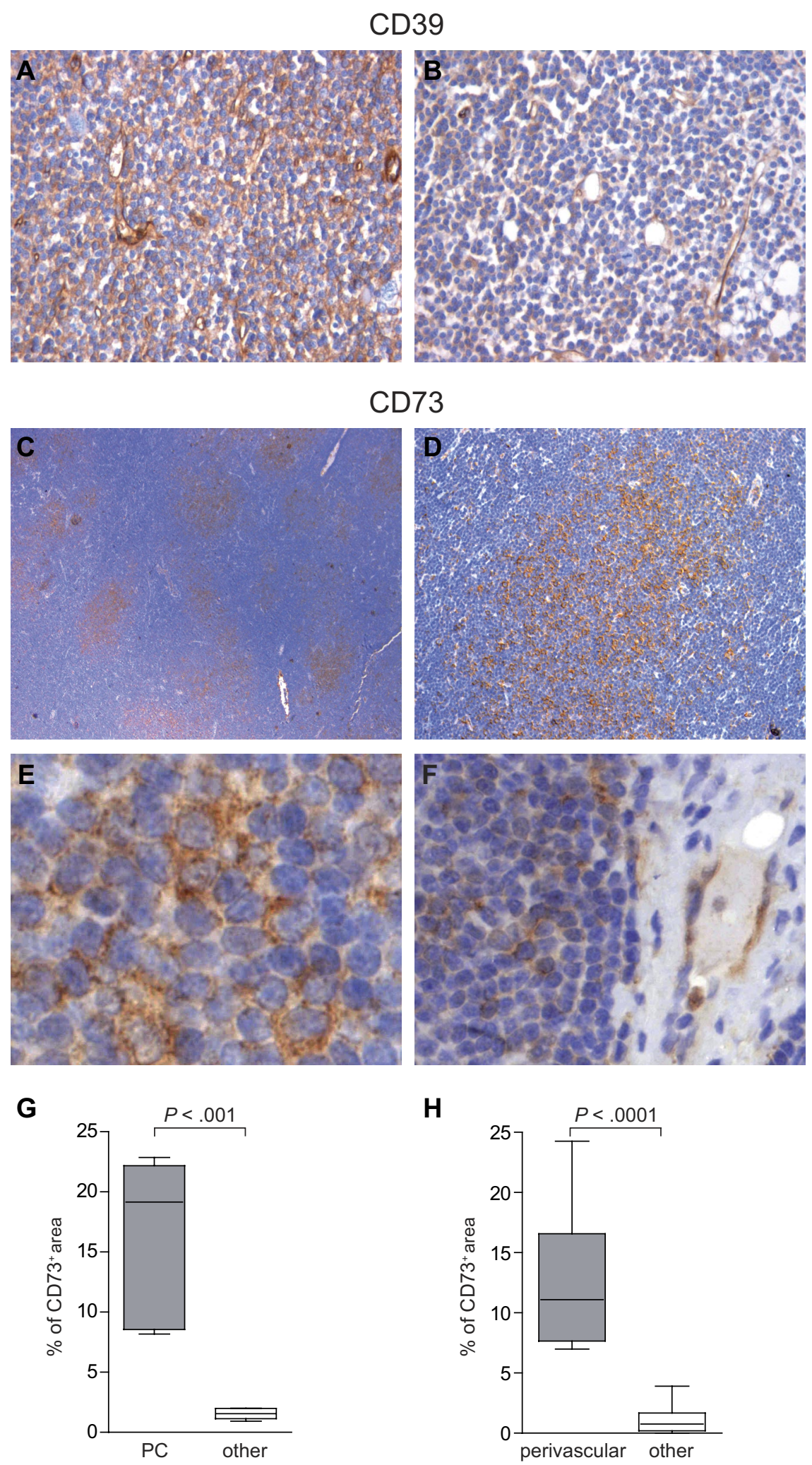

corresponding to the proliferation centers (Figure 1C-E) and in perivascular areas (Figure 1F). The percentage of $\mathrm{CD}^{+} 3^{+}$areas was $16.12 \pm 3.15 \%$ in the proliferation centers and $12.35 \pm 2.11 \%$ in perivascular areas, compared with $1.5 \pm 0.45 \%$ in the rest of the section $(P=.001$ and $P<.0001$, respectively; Figure $1 \mathrm{G}-\mathrm{H})$. At high magnification, $\mathrm{CD}^{+} 3^{+}$cells displayed most commonly the morphologic features of prolymphocytes (Figure 1E).
The proliferation centers are areas of intense proliferation of leukemic cells and heavy infiltration by $\mathrm{T}$ cells, mostly $\mathrm{CD}^{+} /$ $\mathrm{CD} 25^{+}{ }^{6}$ Multicolor immunofluorescence confocal microscopy of $\mathrm{LN}$ tissue sections $(\mathrm{n}=10)$ was used to examine the proliferation centers, based on the presence of high numbers of $\mathrm{Ki}-67^{+} /$ proliferating $\mathrm{CD} 23^{+} / \mathrm{CLL}$ cells in close contact with $\mathrm{CD} 2^{+}$/ T lymphocytes (Figure 2A-B). CD73 and CD23 were almost 
A
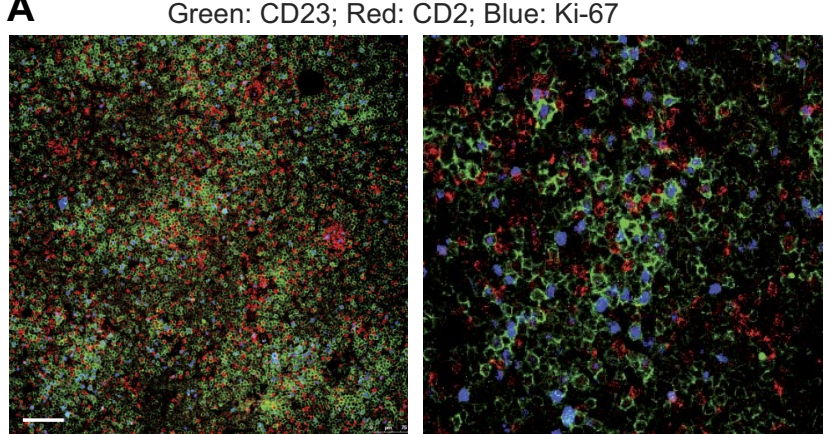

C
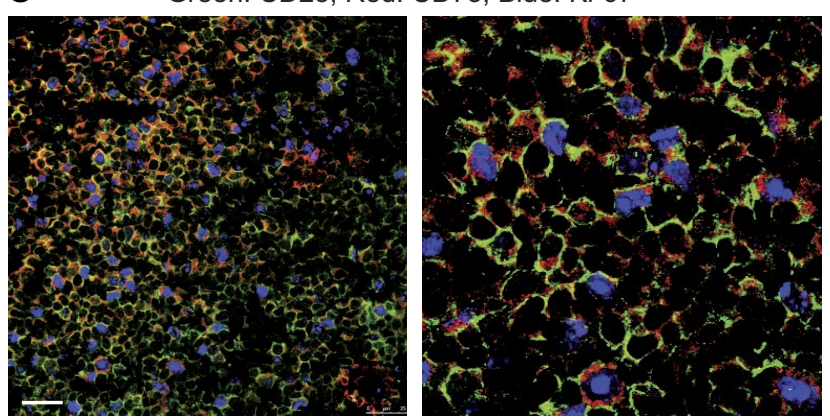

E

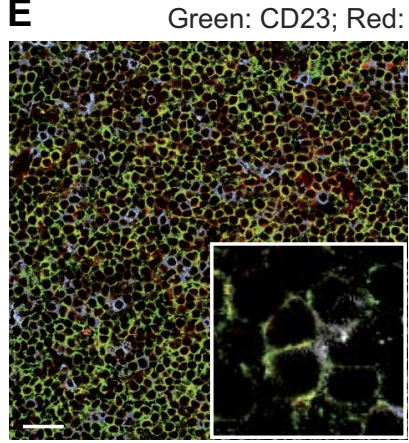

G

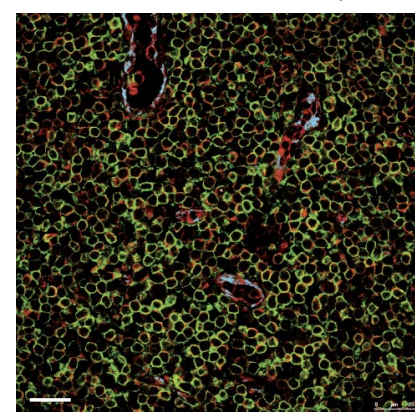

B

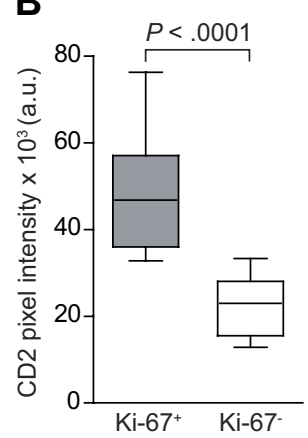

D

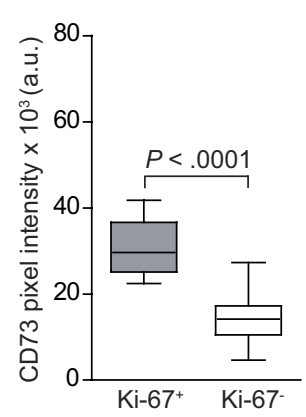

$\mathbf{F}$
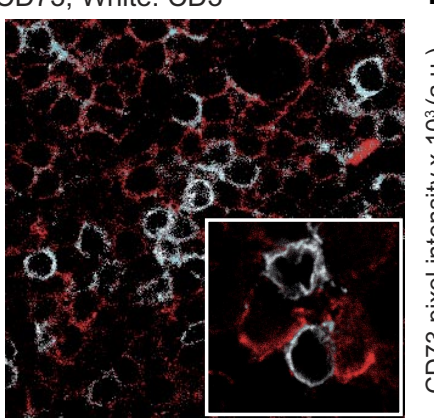

Figure 2. CD73 is expressed by proliferating CLL cells and is enriched in perivascular areas. (A) Triple staining of a representative CLL LN section with antiCD23 (green), anti-CD2 (red), and anti-Ki-67 (blue). CLL proliferation centers are defined as areas enriched in $\mathrm{Ki}-67^{+}$(blue) $\mathrm{CD}^{+} 3^{+}$(green) CLL cells and in CD2 ${ }^{+}$ $\mathrm{T}$ lymphocytes (red). Original magnification $\times 20$ for image on the left and $\times 63$ for that on the right. Scale bar represents $75 \mu \mathrm{m}$. (B) Cumulative analysis of CD2 pixel intensity (arbitrary units, a.u.) indicates that expression is significantly higher in $\mathrm{Ki}-67^{+}$than in $\mathrm{Ki}-67^{-}$areas. (C) Triple staining for CD23 (green), CD73 (red), and Ki-67 (blue). Original magnification $\times 63$; zoom factor of 3 for image on the right. Scale bar represents $25 \mu \mathrm{m}$. (D) Cumulative data of CD73 pixel intensity (a.u.) from $\mathrm{Ki}-67^{+}$and $\mathrm{Ki}-67^{-}$areas. (E) Triple staining (left) for CD23 (green), CD73 (red), and CD3 (white) and double staining (right) for CD73 (red) and CD3 (white). Original magnification $\times 63$; zoom factor of 3 for image on the right. Scale bar represents $25 \mu \mathrm{m}$. (F) Comparative analysis of CD73 pixel intensity (a.u.) in T cell-rich vs T cell-poor areas from different LN sections. (G) Triple staining for CD23 (green), CD73 (red), and CD31 (white). Original magnification $\times 63$; zoom factor of 3 for image on the right. Scale bar represents $25 \mu \mathrm{m}$. (H) Cumulative analysis of CD73 pixel intensity confirms significantly higher intensity in perivascular versus nonperivascular areas. For cumulative analysis, 4 randomly chosen fields from 4 different samples were counted. All samples were analyzed using a TCS SP5 laser scanning confocal microscope (Leica Microsystems) with a $20 \times / 0.5$ and an oil immersion $63 \times / 1.4$ objective lenses, images were acquired with LAS AF Version Lite 2.4 software and processed with Photoshop (Adobe Systems). Pixel intensities were calculated with ImageJ software (freely downloadable at http://rsbweb.nih.gov/ij/), and statistical analysis was performed using Student $t$ test.

exclusively coexpressed, underlying a subpopulation of CLL cells predominantly located in proliferation centers, as shown by more intense staining in $\mathrm{Ki}-67^{+}$areas (Figure $2 \mathrm{C}-\mathrm{D}$ ). $\mathrm{CD} 23^{+} / \mathrm{Ki}-67^{+} /$ $\mathrm{CD} 3^{+}$proliferating CLL cells exhibited a tight spatial relationship with infiltrating T lymphocytes (Figure 2E-F). Quantitative measurements of fluorescence intensity confirmed that proliferation centers contained CLL cells expressing CD73 at higher levels than those found in surrounding areas with low numbers of $\mathrm{Ki}-67^{+}$cells $(P<.0001$; Figure 2D). These studies also indicated that CD73 fluorescence intensity was markedly increased in leukemic cells adherent to $\mathrm{CD} 2^{+}$lymphocytes, compared with CLL cells not associated with T lymphocytes $(P<.0001$; Figure $2 \mathrm{~F})$.

Immunofluorescence studies confirmed that CD73 is highly expressed by endothelial cells ${ }^{12}$ and that $\mathrm{CD} 23^{+} / \mathrm{CD} 73^{+}$leukemic cells are present in perivascular areas, where intense recirculation to and from LNs occurs (Figure 2G). Quantitative data demonstrated a significant difference between the fluorescence intensity of $\mathrm{CD} 23^{+} / \mathrm{CD} 73^{+}$cells in perivascular areas compared with the same cells in other areas of the slide $(P<.0001$; Figure 2H). 
Figure 3. Expression of $C D 39$ and $C D 73$ in a cohort of CLL patients. PBMCs purified from CLL patients were stained with anti-CD19-FITC and anti-CD39-PE or antiCD73-PE. (A) Representative density plots from 2 different samples. Cumulative data on the percentage of double-positive cells or the MFI are reported in panels B and $C$, respectively. $n=35$. (D) RT-PCR data on the mRNA levels of CD39 and CD73 in the same cohort of patients. $\mathrm{n}=35$. Mean values of expression are represented as a horizontal line. (E-F) Correlation between the expression of CD73 and CD38 $(n=299)$ and CD73 and ZAP-70 $(n=295)$, adopting the arbitrary cut-off value of $20 \%$. (G) Percentage of $\mathrm{CD} 19^{+} / \mathrm{Ki}-67^{+}$cells in a subset of patients characterized by low $(<10 \%)$ and high $(>70 \%)$ $\mathrm{CD} 73$ expression. Data in panels $\mathrm{E}$ to $\mathrm{G}$ are expressed as box plot, where the top and the bottom of the box represent the first and the third quartiles, respectively; the horizontal line within the box indicates the median; and the whiskers represent the mean \pm SEM. Statistical analysis was performed using Student $t$ and MannWhitney U tests.
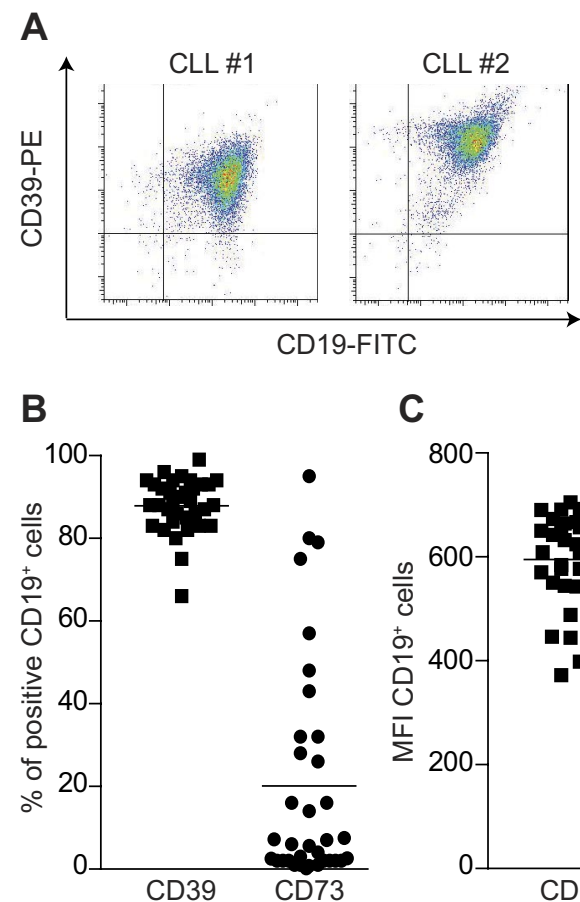

C

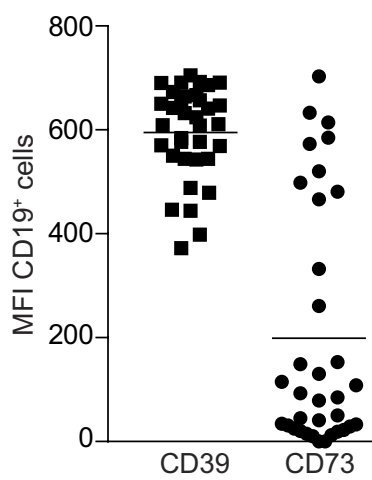

D

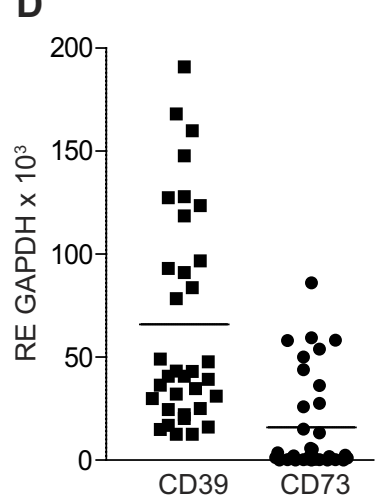

F

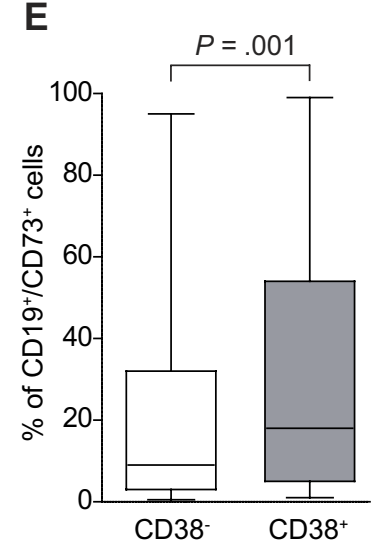

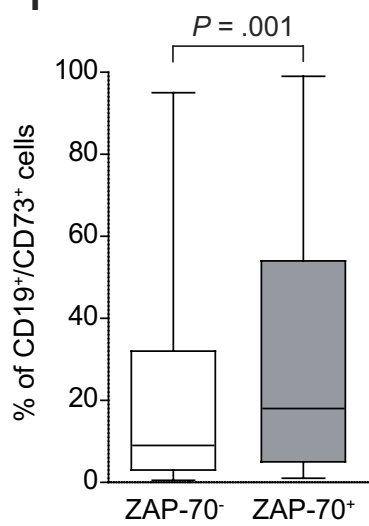

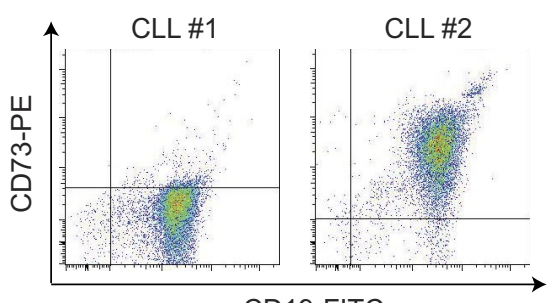

CD19-FITC
G

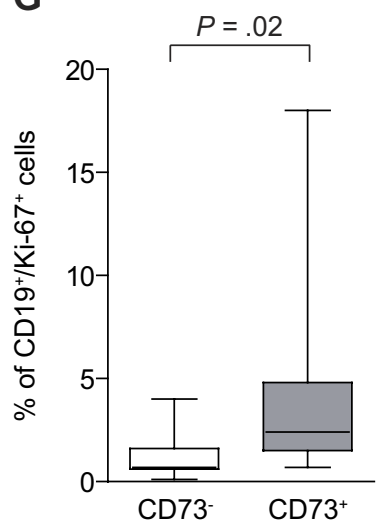

CD73 expression in circulating CLL cells is heterogeneous and associates with molecular markers linked to a more aggressive disease

We then evaluated whether CD39 and CD73 expression was maintained by circulating CLL cells, as first examined in a pilot cohort of 35 CLL patients. CD39 was constantly present at high levels in the majority of neoplastic CD19+ lymphocytes (mean \pm SEM percentage of expression, $88 \pm 6 \%$ ), with minor variations in the mean fluorescence intensity (MFI; mean, $612 \pm 75$; Figure $3 \mathrm{~A}-\mathrm{C})$. In contrast, CD73 was variably expressed by the leukemic cells, with $21 / 35$ patients ( $60 \%$ of the cohort) with less than $10 \%$ of $\mathrm{CD} 19^{+} / \mathrm{CD} 73^{+}$cells in the peripheral blood (mean \pm SEM percentage of expression, $20 \pm 27 \%$; Figure $3 \mathrm{~A}-\mathrm{C}$ ). RT-PCR data confirmed that CD39 mRNA was highly expressed in all samples, although with quantitative samples variations, whereas CD73 showed undetectable to low levels in approximately half of the patients examined $(18 / 35,51 \%$; Figure 3D).

CD73 expression was generally stable over time, as determined by checking surface levels of the molecule in samples obtained from the same patient, after at least a 6-month time interval without intervening therapies ( $P=.45$; supplemental Figure 1A).

To confirm these findings, expression of CD73 was then tested on the $\mathrm{CD}_{19}{ }^{+}$subset of a larger CLL cohort $(\mathrm{n}=299)$. These studies confirmed that $\sim 30 \%$ of patients have clearly identifiable $\mathrm{CD} 9^{+} / \mathrm{CD} 3^{+}$populations (mean $\pm \mathrm{SEM}$ percentage of expression, $25.4 \pm 28 \%$; supplemental Figure 1B). CD73 expression was significantly higher on the $\mathrm{CD} 38^{+}$subset compared with the CD38 ${ }^{-}$counterparts $(P=.001$; Figure $3 \mathrm{E})$. The same difference in expression was observed among cohorts of ZAP-70 ${ }^{+}$and ZAP-70 ${ }^{-}$ patients $(P=.001$; Figure $3 \mathrm{~F})$. In line with immunohistochemical data, a subset of CLL clones $(n=15)$ selected on the basis of high expression of CD73 $(>70 \%)$ displayed significantly higher levels of $\mathrm{CD} 19^{+} / \mathrm{Ki}-67^{+}$compared with the $\mathrm{CD} 73$ low $(<10 \%)$ counterpart $(\mathrm{n}=10)$, that latter or which expressed low levels of $\mathrm{CD} 19^{+} / \mathrm{Ki}-67^{+}$leukemic lymphocytes $(4.06 \pm 1.32 \%$ vs $1.27 \pm 0.49 \% ; P=.02$; Figure $3 \mathrm{G})$. These results demonstrate that CD73 expression marks the CLL subset characterized by a more intense recirculation to and from 
A

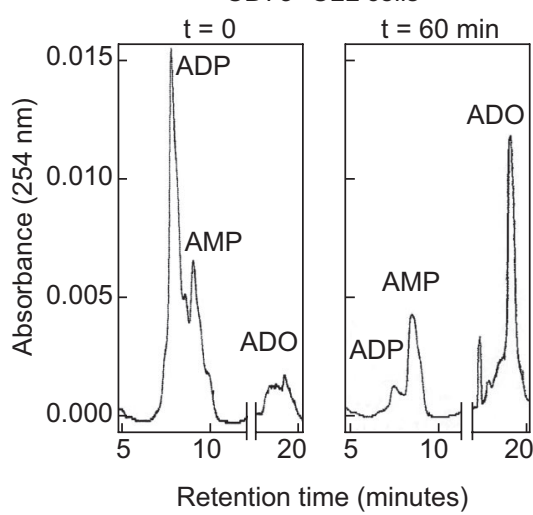

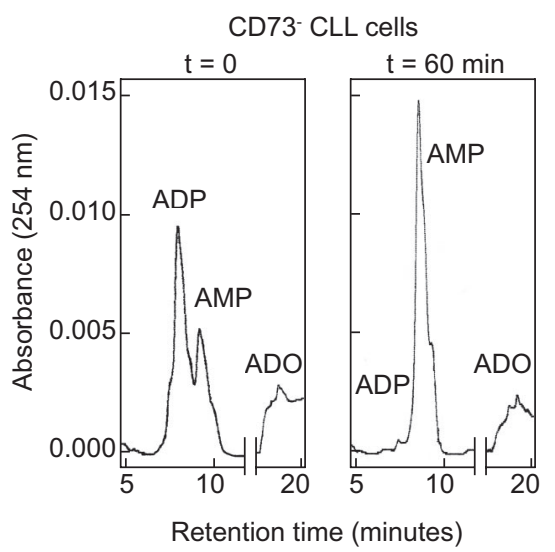

Figure 4. $\mathrm{CD} 39^{+} / \mathrm{CD} 73^{+} \mathrm{CLL}$ cells generate $\mathrm{ADO}$ from ADP. An HPLC assay was adopted to follow the enzymatic conversion of ADP to AMP (CD39 dependent) and to $\mathrm{ADO}$ (CD73 dependent). (A) Representative $\mathrm{CD}^{+} 9^{+}$ $\mathrm{CD}^{+} 3^{+}$(left) and $\mathrm{CD} 39^{+} / \mathrm{CD}^{-} 3^{-}$(right) patients are shown at $t=0$ and after 60 minutes of incubation with $100 \mu \mathrm{M}$ ADP under physiologic conditions. ADP, AMP, and ADO are shown in a single HPLC run. Cumulative data of ADO production in presence or absence of $10 \mu \mathrm{M} \mathrm{APCP}(\mathrm{B})$, ADP consumption (C), or AMP production (D) in $\mathrm{CD}^{-}$ and $\mathrm{CD}_{73}{ }^{+} \mathrm{CLL}$ patients. A functional cut-off for $\mathrm{CD} 73$ expression was designated at $30 \%$. Peak identities were confirmed by comparing the retention times and the UV spectra of samples with standard compounds. Concentrations were calculated by comparing the peak area of samples with calibration curves for peak areas of each standard. All concentrations are expressed as micromoles per hour per $10^{6}$ cells. Statistical analysis was performed using Mann-Whitney $U$ test. $n=20$.
B

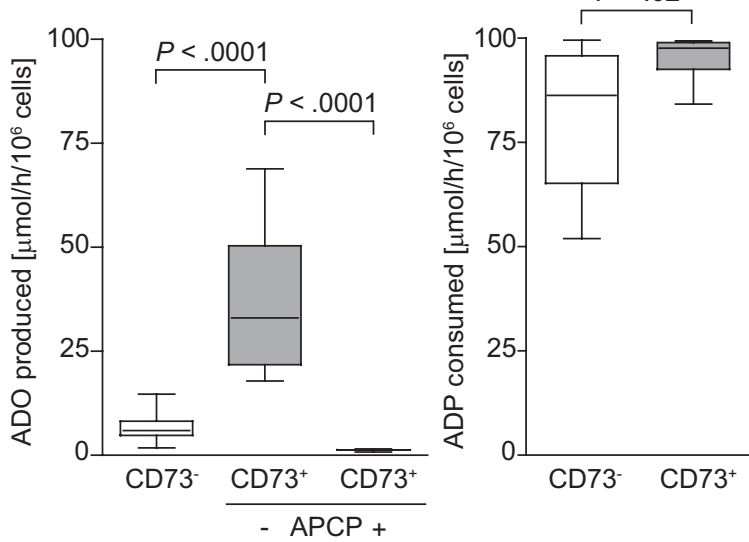

D

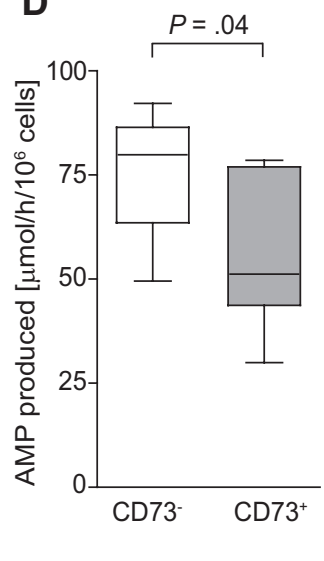

lymphoid organs, by a more aggressive clinical behavior and by a higher cellular turnover.

\section{$\mathrm{CD}^{2} 9^{+} / \mathrm{CD} 3^{+}{ }^{+} \mathrm{CLL}$ cells produce ADO}

We then asked whether $\mathrm{CD} 39^{+} / \mathrm{CD} 3^{+}$circulating CLL lymphocytes could efficiently synthesize ADO. A quantitative HPLC assay was used to measure the substrates (ADP and AMP) and the final product (ADO) in a single HPLC run. Purified CLL cells from patients expressing homogeneous levels of CD39, but CD73 at variable intensity, were incubated (for 1 hour at $37^{\circ} \mathrm{C}$ and $5 \% \mathrm{CO}_{2}$ ) with ADP as the substrate (final concentration, $100 \mu \mathrm{M}$ ), using an adenosine deaminase-free medium. Supernatants were collected and deproteinized before loading in the HPLC equipment. Results indicate that $\mathrm{ADO}$ was selectively produced by CD73+ CLL clones (Figure 4A). Under these experimental conditions, more than $30 \%$ of positive cells served as the best functional cut-off for CD73 expression (Figure 4A-B). The subset of patients expressing more than $30 \% \mathrm{CD} 73$ (indicated as $\mathrm{CD}^{+} 3^{+}$) invariably catalyzed the production of more than $20 \mu \mathrm{mol}$ of $\mathrm{ADO} / \mathrm{h} / 10^{6}$ cells. In contrast, none of the CLL cells expressing less than $30 \% \mathrm{CD} 73\left(\mathrm{CD} 73^{-}\right)$ produced more than $20 \mu \mathrm{mol} \mathrm{ADO} /$ hour $/ 10^{6}$ cells $(P<.0001$; Figure 4B). Moreover, all CLL cells could degrade ADP to AMP, confirming that CD39 is enzymatically active. However, when patients were stratified on the basis of CD73 expression, CD73 ${ }^{+}$ cells consumed significantly more ADP, probably in view of the lack of a feedback inhibitor mechanism driven by AMP accumulation $(P=.02$; Figure $4 \mathrm{C}) .{ }^{26}$ Consistently, AMP levels were higher in the $\mathrm{CD}_{73}^{-}$than in the $\mathrm{CD}^{+} 3^{+}$subset of patients, indirectly supporting the notion of an impairment in the pathway leading to $\operatorname{ADO}(P=.04$; Figure 4D).

Preincubation of $\mathrm{CD}^{+} 3^{+}$CLL cells with APCP, a known inhibitor of CD73 enzymatic activities, significantly inhibited ADO production, confirming that $\mathrm{CD} 73$ is the predominant AMPase $(P<.0001$; Figure 4B). The same treatment had no effect on the CD39-dependent ADP to AMP conversion or on CD73- CLL cells (data not shown).

These results demonstrate that the enzymatic cascade leading to $\mathrm{ADO}$ synthesis is selectively active in $\mathrm{CD} 73^{+}$CLL cells that might be predicted to have poor prognostic features. They also identify $30 \%$ of surface expression as a functional cut-off for CD73.

\section{A2A receptor is expressed by CLL cells}

Physiologically, extracellular ADO can either be rapidly internalized or can bind P1 receptors. ${ }^{27}$ RT-PCR analyses showed selectively high levels of the A2A receptor $(P<.0001$; Figure 5A), the receptor that is the most commonly involved in anti-inflammatory and antitumor responses. ${ }^{27}$ Expression of A1, A2B, and A3 receptors was invariably low to undetectable (Figure 5A). Furthermore, A2A receptor mRNA was present at significantly higher levels in CLL patients than in normal B lymphocytes purified from peripheral blood of sex- and age-matched healthy donors $(P=.001$; Figure 5B). A2A expression was apparently independent of surface CD73 levels $(P=.45$; data not shown), suggesting that the enzyme per se represents the limiting factor in the adenosinergic axis of CLL lymphocytes. 
Figure 5. Expression of type 1 ADO receptors by CLL cells. Purified leukemic cells from CLL patients were analyzed for the expression of the 4 known ADO receptors. (A) RT-PCR data on the mRNA levels of A1, A2A, $A 2 B$, and $A 3$ receptors. $n=35$. (B) A2A levels in CLL patients $(n=35)$ were compared with sex- and agematched individuals without evidence of CLL $(n=8)$. (C) Ligation of A2A with the selective agonist CGS21680 $\left(10 \mu \mathrm{M}\right.$, for 30 minutes at $\left.37^{\circ} \mathrm{C}\right)$ induces a significant increase in intracellular cAMP levels in basal conditions and on treatment with CpG/IL-2 $(1 \mu \mathrm{g} / \mathrm{mL}$ and $100 \mathrm{IU} / \mathrm{mL}$, respectively) for 48 hours. $n=8$. (D) RT-PCR analysis of A2A expression in freshly purified CLL cells (basal) or in cells cultured for 48 hours with or without CpG/IL-2. $\mathrm{n}=9$. The Mann-Whitney $U$ test was used to determine statistical significance. CGS indicates CGS21680.

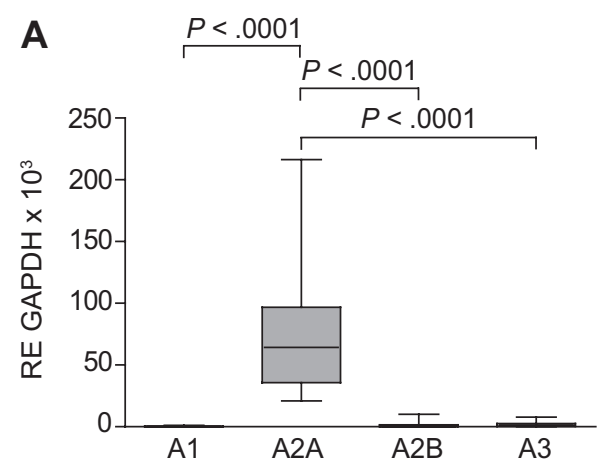

B
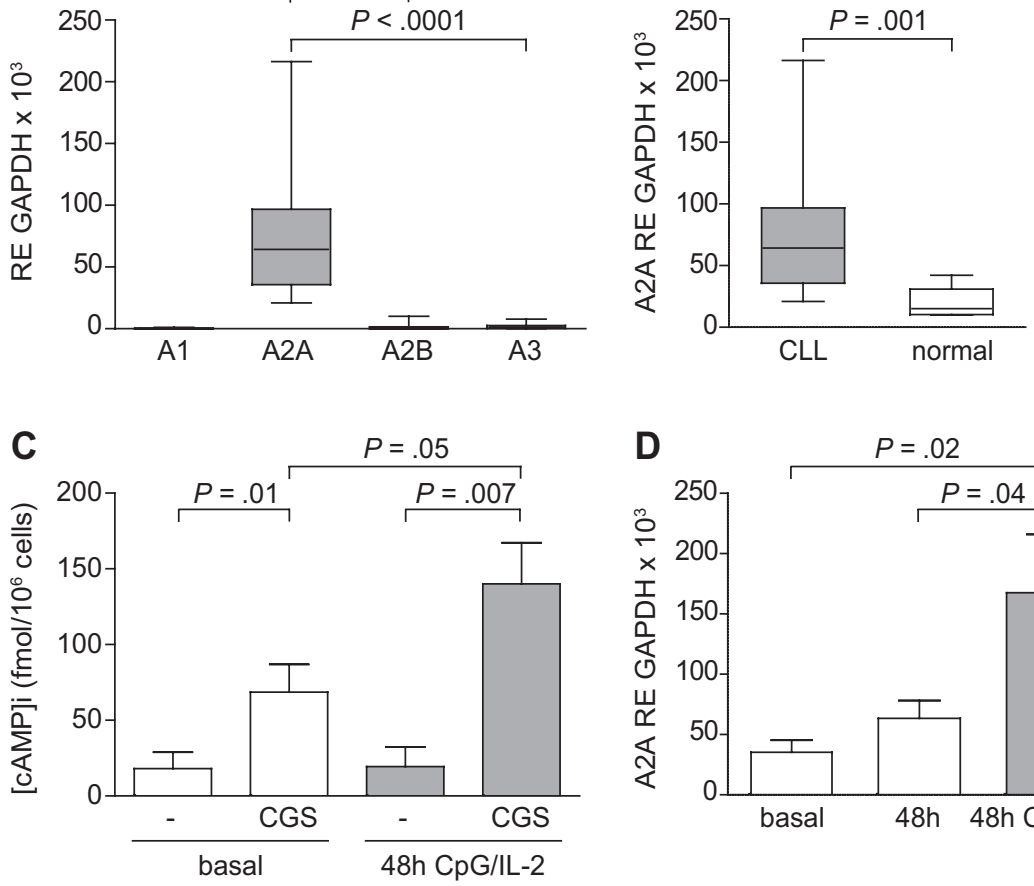

$\mathrm{ADO}$ binding to the $\mathrm{A} 2 \mathrm{~A}$ receptor leads to the activation of the coupled stimulatory $\mathrm{G}$ protein and to the consequent increase of intracellular cAMP concentrations. Consistently, ligation of A2A with the specific agonist CGS21680 was followed by a significant increase in cytoplasmic cAMP levels, confirming that the receptor expressed by CLL cells is functional ( $P=.01$; Figure $5 \mathrm{C})$.

The levels of the A2A receptor were next tested in purified CLL cells activated in vitro using Toll-like receptor-9 (TLR-9) agonists and IL-2, to promote maximal activation and proliferation of CLL cells. The results indicate that A2A mRNA levels significantly increased after activation of CLL cells $(P=.02$ compared with baseline levels and $P=.04$ compared with CLL cultured for 48 hours; Figure 5D). In agreement with the expression data, activated CLL cells showed increased cAMP levels compared with nonactivated CLL cells when exposed to the A2A agonist CGS21680 $(P=.05 ;$ Figure 5C).

\section{ADO inhibits CLL cell chemotaxis}

We then focused on the role played by extracellular ADO in CLL homeostasis, in keeping with the hypothesis that this nucleoside works as an autocrine factor in closed systems. The finding of higher CD73 levels on cells in perivascular areas, along with the preferential expression of $\mathrm{CD} 73$ in the $\mathrm{CD} 38^{+} / \mathrm{ZAP}-70^{+}$recirculating CLL subset, suggests that the ATP-ADO axis modulates chemotactic responses of CLL cells. CXCL12 was used as prototype chemokine, because it drives CLL recirculation to and from lymphoid organs. ${ }^{28}$ Addition of ADO significantly hampered cell motility toward the CXCL12 chemokine in a dose-dependent way, and maximal inhibition was observed at ADO levels of $50 \mu \mathrm{M}$ (mean, $0.45 ; P=.03$; Figure 6A). The same effect was obtained after pretreating CLL cells with the A2A agonist CGS21680, suggesting that activation of the $\mathrm{A} 2 \mathrm{~A}$ receptor and the consequent increase in intracellular cAMP levels are necessary steps to stop chemokine-driven cell migration (mean, $0.46 ; P=.03$; Figure $6 \mathrm{~A}$ ).
The essential role of CD73 was shown using the specific APCP inhibitor to block the enzymatic activity, leading to significantly increased chemotactic responses with removal of ADO (mean, $1.36 ; P=.02 ;$ Figure $6 \mathrm{~A}$ ). The effect was reversed in the presence of extracellular ADO, suggesting that in this system the main contribution of CD73 to chemotaxis is via ADO production through its enzymatic activity (mean, $0.74 ; P=.002$; Figure $6 \mathrm{~A}$ ). The blocking effects mediated by APCP were only apparent when using $\mathrm{CD}_{73^{+}}$CLL cells; no modification was observed when testing $\mathrm{CD}^{-} 3^{-}$cells (data not shown). These results are in line with evidence obtained in other models and suggest that nucleosides act as short-range signals causing cells that have been attracted by long-range chemokines to stop where the chemokine concentrations are highest. ${ }^{29}$ One of the proposed mechanisms for ADO to impair chemotaxis is by down-regulating CXCR 4 expression. ${ }^{30} \mathrm{In}$ line with this view, the $\mathrm{CD} 73^{+}$subset of a selected cohort of CLL patients $(\mathrm{n}=45)$ expressed CXCR4 at significantly lower intensity than the $\mathrm{CD}^{-} 3^{-}$counterpart $\left(\mathrm{CXCR} 4 \mathrm{MFI}\right.$ in the $\mathrm{CD} 73^{+}$subset $534.7 \pm 20.79$ vs $621.9 \pm 18.8$ in the $\mathrm{CD}^{-}$subset, $P=.007$; Figure 6B). No significant differences were observed in the percentage of $\mathrm{CXCR} 4^{+}$cells (mean $\pm \mathrm{SEM}$ percentage of expression in the $\mathrm{CD}^{+} 3^{+}$subset, $86.46 \pm 1.57 \%$ vs $86.67 \pm 1.34 \%$ in the $\mathrm{CD}^{-}{ }^{-}$subset; $P=.38$; Figure $\left.6 \mathrm{C}\right)$.

\section{ADO is part of an autocrine signaling loop that protects CLL cells from spontaneous and drug-induced apoptosis}

Attention was then focused on the role of the adenosinergic axis in modulating CLL apoptosis. Addition of extracellular ADO to cultures of purified CLL cells significantly inhibited spontaneous apoptosis, with the maximal effects observed at $50 \mu \mathrm{M}(P=.02$; Figure 7A), within the range of concentrations measured in the HPLC studies. Apoptosis inhibition was highlighted after 16 hours and then decreased progressively, suggesting that the molecule is rapidly consumed (data not shown). 
A
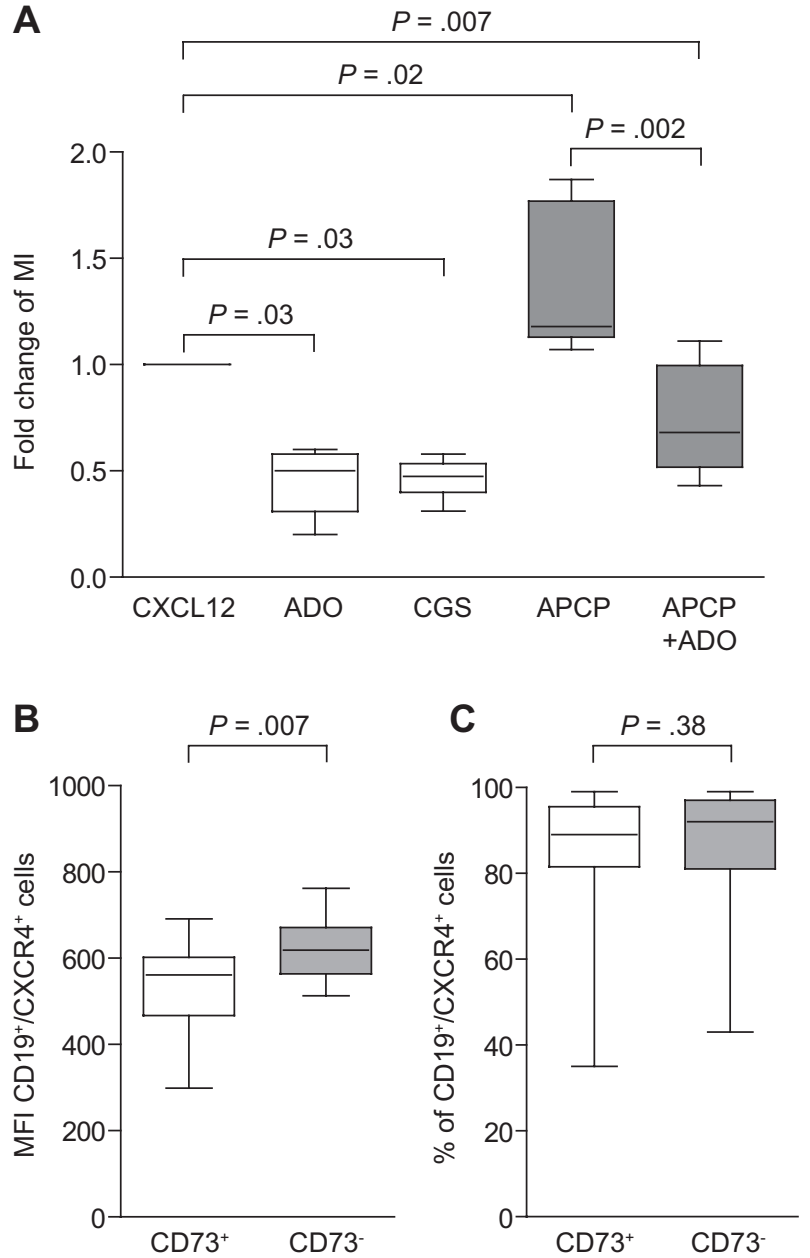

Figure 6. ADO inhibits CLL chemotaxis in response to CXCL12. (A) A conventional chemotaxis assay with Boyden chamber was adopted, using CXCL12 $\left(60 \mathrm{ng} / 10^{6} \mathrm{cells} /\right.$ well) as chemoattractant, in the presence or absence of ADO $(50 \mu \mathrm{M})$ for the whole length of the assay (4 hours). Where indicated, cells were pretreated with CGS21680 $\left(10 \mu \mathrm{M}\right.$, for 30 minutes at $\left.37^{\circ} \mathrm{C}\right)$ or APCP $(10 \mu \mathrm{M}$, for 60 minutes at $37^{\circ} \mathrm{C}$ ). Data are presented as fold increase or decrease, considering 1 the $\mathrm{Ml}$ of the cells in the presence of $\mathrm{CXCL} 12$ alone. $n=8$. (B-C) MFI and percentage of expression of CXCR4 in a cohort of 40 patients $\left(20 \mathrm{CD}^{+} 3^{+}\right.$and $20 \mathrm{CD}^{-} 3^{-}$on the basis of the $30 \%$ functional cut-off). Data are expressed as box plot, where the top and the bottom of the box represent the first and the third quartiles, respectively; the horizontal line within the box indicates the median; and the whiskers represent the mean \pm SEM. Statistical analysis was performed using the Mann-Whitney $U$ test.

An antiapoptotic effect of ADO was also apparent when cells were treated with chemotherapeutic agents. Etoposide was selected as a DNA-damaging agent that robustly triggered apoptosis already after 16 hours (Figure 7B). ADO added at the beginning of the culture yielded a highly significant and dose-dependent protective effect (mean \pm SEM percentage of apoptosis in etoposide-treated cells, $48 \pm 16 \%$ vs $36 \pm 13 \%$ with the etoposide/ADO combination; $P=.03$; Figure $7 \mathrm{~B}$ ). Treatment with the selective A2A agonist CGS21680 indicated that the protection from apoptosis induced by ADO is mainly mediated via activation of the A2A receptor (mean \pm SEM percentage of apoptosis in etoposidetreated cells, $48 \pm 16 \%$ vs $34 \pm 12 \%$ with the etoposideCGS21680 combination; $P=.05$; Figure 7B). Consistently, inactivation of the $\mathrm{A} 2 \mathrm{~A}$ receptor by pretreatment with the selective antagonist SCH58261 abrogated protection from apoptosis (mean \pm SEM of apoptosis in etoposide-CGS21680-treated cells, $34 \pm 12 \%$ vs $55 \pm 3 \%$ with the etoposide-SCH58261-CGS21680 combination; $P=.02$; Figure 7B). The effects derived from targeting the adenosinergic axis downstream of CD73 were comparable in the $\mathrm{CD} 73^{+}$and $\mathrm{CD} 73^{-}$CLL subsets, in keeping with a relatively homogeneous A2A expression by CLL cells.

Treatment with APCP, the specific inhibitor of CD73, provoked a modest increase in spontaneous apoptosis (mean \pm SEM percentage of spontaneous apoptosis, $25 \pm 8 \%$ vs $32 \pm 5 \%$ with APCP; $P=.14$ ), selectively in CD73 ${ }^{+}$CLL cells, then used for this set of experiments (Figure 7C). CD73 blockade in the presence of etoposide significantly increased apoptosis (mean \pm SEM percentage of apoptosis in etoposide-treated cells, $48 \pm 14 \%$ vs $67 \pm 7 \%$ in the etoposide-APCP combination; $P=.01$; Figure $7 \mathrm{C}$ ). The synergistic effect was corrected by exogenous ADO, confirming that CD73 is necessary for ADO generation by CLL cells (mean \pm SEM percentage of apoptosis in the etoposide-APCP combination, $67 \pm 7 \%$ vs $49 \pm 9 \%$ with etoposide-APCP-ADO; $P=.008$; Figure 7C).

Comparable effects were also measured after exposing purified CLL cells to fludarabine, a widely used drug in the therapy of CLL patients. The onset of apoptosis after fludarabine exposure is slower than with etoposide, with effects evident 48 to 72 hours after beginning of cultures. Addition of ADO at the beginning of the cultures resulted in a statistically significant inhibition of apoptosis, which was even more evident if ADO was added repetitively at 12 hours intervals, in keeping with the notion that extracellular ADO is rapidly consumed or taken up by cells (mean \pm SEM percentage of apoptosis in fludarabinetreated cells, $55 \pm 17 \%$ vs $19 \pm 5 \%$ in the fludarabine-ADO combination; $P=.001$; Figure 7D). ADO protection was dependent on the presence of functional A2A receptors, as shown using the selective agonist CGS21680. This compound inhibited the apoptotic process, even if it did not achieve levels seen with ADO (mean \pm SEM percentage of apoptosis in fludarabinetreated cells, $55 \pm 17 \%$ vs $29 \pm 6 \%$ in the fludarabine-CGS combination; $P=.006$; Figure 7D). Inactivation of A2A receptor by pretreatment with the antagonist SCH58261 rendered CLL cells insensitive to CGS21680 protective effects (data not shown). CD73 blockade induced by APCP treatment led to a significant increase in the apoptotic rate, as observed in the case of etoposide (mean \pm SEM percentage of apoptosis in fludarabine-treated cells, $55 \pm 17 \%$ vs $75 \pm 20 \%$ in the fludarabineAPCP combination; $P=.04$; Figure 7D). Although effects induced by ADO and by pharmacologic targeting of the A2A receptor were independent of CD73 expression, APCP was active only on the $\mathrm{CD}^{+} 3^{+}$subset.

These results indicate that $\mathrm{ADO}$ may act, at least in part, through the activation of the $\mathrm{A} 2 \mathrm{~A}$ receptor increasing intracellular cAMP levels. This mechanism has been linked to inactivation of the 553 pathway in neoplastic B cells. ${ }^{31}$ In line with this hypothesis, Western blot analyses showed that the addition of ADO in combination with etoposide significantly decreased the activation of Mcl-1 and BAX, 2 p53-dependent proteins in the pathway leading to the activation of caspase-3 ( $P=.01$; Figure 7E-F). Accordingly, the association of etoposide and ADO significantly increased the inactive form of caspase-3 (Figure 7E-F). Similar effects were obtained by combining etoposide with the CGS21680 agonist, underlining the relevance of the $\mathrm{A} 2 \mathrm{~A}$ receptor in protecting from apoptosis $(P=.04)$. Lastly, the combination of etoposide and APCP significantly increased the apoptosis compared with etoposide alone $(P=.02$; Figure $7 \mathrm{E}-\mathrm{F})$. 
Figure 7. Extracellular ADO protects from both spontaneous and drug-induced apoptosis. (A) Purified CLL cells were plated with or without extracellular ADO at the indicated doses. The percentage of apoptotic cells was determined after 16 hours. $n=10$. (B) CLL cells were cultured in the presence of etoposide $(50 \mu \mathrm{M})$ in combination with $\mathrm{ADO}(50 \mu \mathrm{M})$. Where indicated, CLL cells were pretreated with CGS21680 $(10 \mu \mathrm{M}$, for 30 minutes at $37^{\circ} \mathrm{C}$ ) alone or in combination with SCH58261 $(10 \mu \mathrm{M}$, for 30 minutes at $\left.37^{\circ} \mathrm{C}\right) \cdot \mathrm{n}=10$. (C) $\mathrm{CD} 73$ enzymatic activity was blocked using the APCP inhibitor $(10 \mu \mathrm{M}$, for $60 \mathrm{~min}$ utes at $37^{\circ} \mathrm{C}$ ). Pretreatment of CLL cells with APCP in the presence of etoposide $(50 \mu \mathrm{M})$ significantly increase the apoptotic rate, corrected by the addition of exogenous $\operatorname{ADO}(50 \mu M) \cdot n=10$. (D) Purified CLL cells were treated with fludarabine $(5 \mu \mathrm{M})$, alone or in combination with ADO $(50 \mu \mathrm{M})$, and apoptosis was evaluated after 48 hours. Where indicated, CLL cells were pretreated with CGS21680 or APCP $(10 \mu \mathrm{M}$, for 30 minutes and $60 \mathrm{~min}$ utes at $37^{\circ} \mathrm{C}$, respectively). $n=10$. (E) Western blot analysis of the expression of the p53-dependent genes Mcl-1, BAX, and caspase-3, after the exposure of CLL cells to etoposide $(50 \mu \mathrm{M})$ as DNA-damaging agent. (F) Quantitative analysis of caspase-3 expression. Fold change is represented as the ratio of each treatment on the basal condition. $n=5$. Error bars represent the SEM in all the graphs. Statistical analysis was performed using Student $t$ or Wilcoxon signed rank tests. SCH indicates SCH58261; ETO, etoposide; and FLUDA, fludarabine.
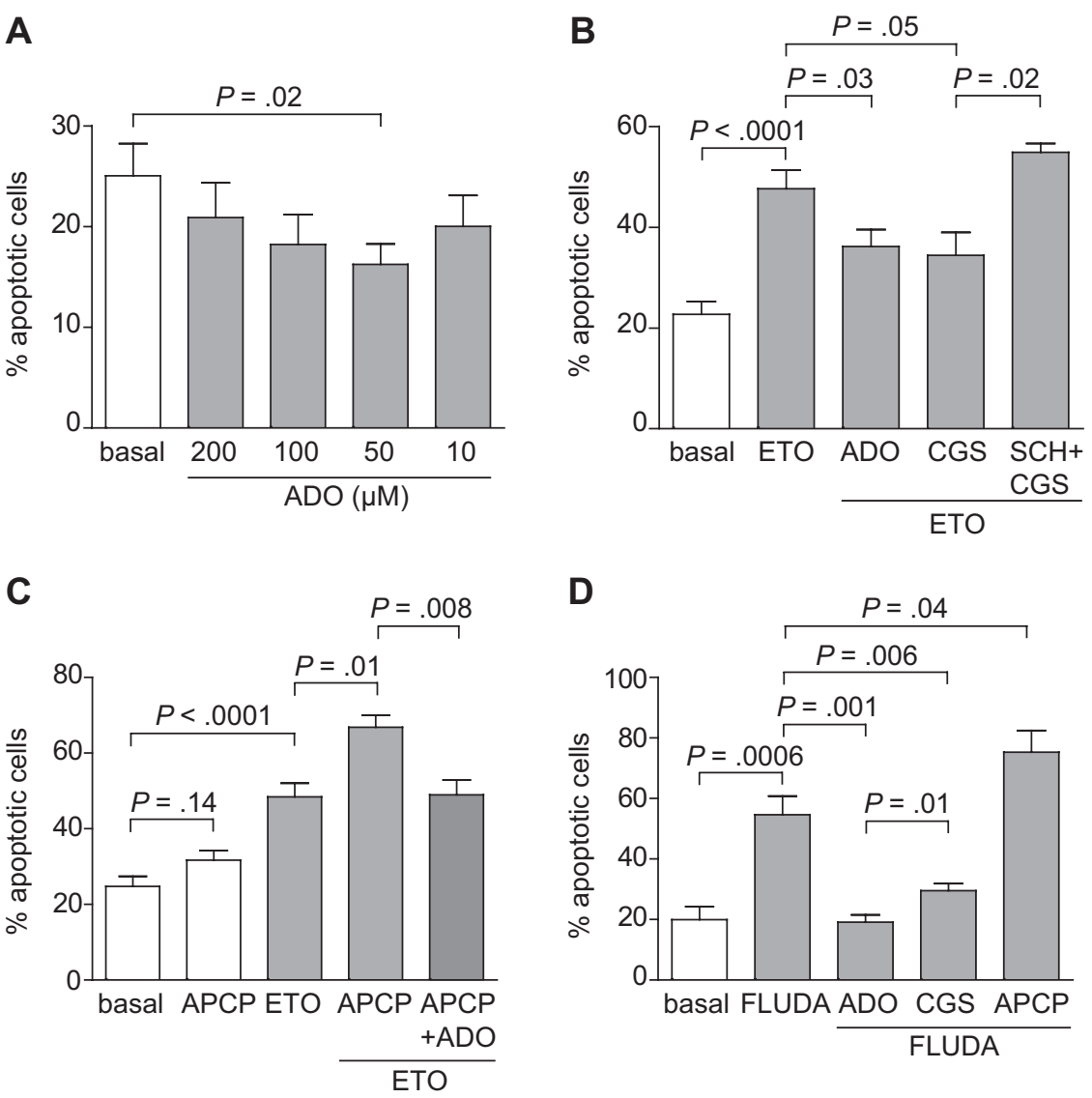

E

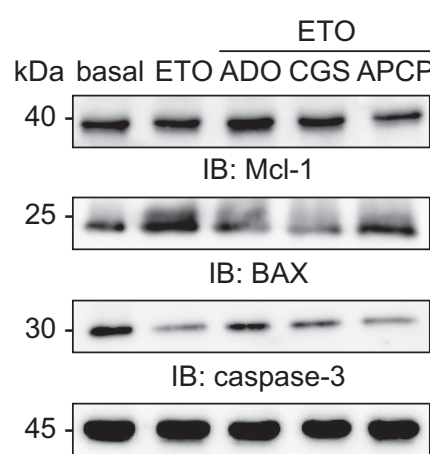

IB: actin

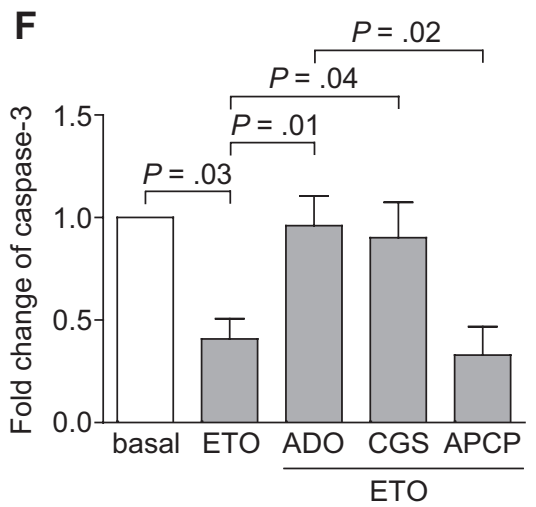

\section{Discussion}

CLL cells show markedly distinct behaviors in the blood or in the LNs, with proliferation occurring almost exclusively in the latter. These observations suggest that local microenvironments provide elements and conditions supporting growth, diffusion, and resistance to therapy. Results of this work support the view that the adenosinergic axis composed by the ectoenzymes CD39 and CD73 and by type 1 purinergic receptors modulate these processes. When analyzed in the LN microenvironment, CD39 is widely expressed by neoplastic cells, as well as by surrounding nonneoplastic stroma. On the contrary, CD73 is mostly restricted to CLL proliferation centers and confined to cells with a prolymphocyte and paraimmunoblast morphology, suggesting that ADO generation is confined to specific tissue niches and to specific cell subpopulations therein. When analyzed in the peripheral blood,
CD39 is constantly expressed at high levels by CLL cells, confirming previous data. ${ }^{32}$ Approximately one-third of patients have a distinguishable subpopulation of $\mathrm{CD} 19^{+} / \mathrm{CD} 3^{+}$cells, confirming the indications coming from tissue biopsies and from selected previous studies using smaller cohorts. ${ }^{33,34}$ The $\mathrm{CD} 73^{+}$ patient subset is characterized by increased expression of CD38 and of ZAP-70, both negative prognostic markers, ${ }^{35,36}$ and functionally involved in the regulation of CLL homing to the $\mathrm{LN}$ microenvironment. ${ }^{25,37}$ The $\mathrm{CD}^{+} 3^{+}$subset also is enriched in $\mathrm{Ki}-67^{+}$(proliferating) CLL cells, suggesting that it is characterized by an increased CLL cell turnover.

The contribution of CD73 to the formation of ADO has been revealed in several experimental models ${ }^{38,39}$ and is confirmed in this work. Extracellular ADO is produced by purified CLL cells in amounts compatible with the range of concentrations that have been measured in tumor tissues. ${ }^{40}$ Blockade of CD73 biochemical activity by a specific inhibitor blunts ADO production, indicating 
that $\mathrm{CD} 73$ is the main surface ectoenzyme generating ADO in CLL. Considered together, the tissue distribution and enzymatic data suggest that (1) CD73 functions as a rate limiting enzyme in the activation of the adenosinergic axis and that (2) ADO production is critically restricted by CD73 expression, in turn tightly regulated by environmental signals. ${ }^{41-43}$ The conclusion is that ADO production is mostly confined to the proliferation centers of the CLL LNs.

ADO exerts a variety of anti-inflammatory effects mediated by 4 specific type 1 purinergic receptors. CLL cells constitutively express high levels of the A2A receptor, further increased in proliferating leukemic cells. The signaling pathway initiated by A2A leads to increased cytoplasmic cAMP levels that modulate different signaling pathways. ${ }^{14} \mathrm{~A} 2 \mathrm{~A}$ activation was demonstrated in resting CLL cells treated in vitro with a selective agonist and found increased during proliferative responses.

Considered in a global view of the disease, these findings suggest that the adenosinergic axis is mostly active in tissue niches where extracellular nucleotides are elevated as a consequence of enhanced cellular turnover, the enzymatic machinery is expressed and the downstream receptors are present at high levels. Multicolor confocal microscopy confirms that CD73 expression is typically associated with proliferating CLL cells that display privileged interactions with neighboring nonneoplastic T cells. ${ }^{44}$ Our second finding is that CD73 expression by CLL cells is high in perivascular areas, suggesting that the molecule is involved in chemotaxis and homing processes. ${ }^{45}$

Using CXCL12 as chemoattractant, we show that CD73generated ADO inhibits migration, via activation of the A2A receptor, in line with models that propose that the adenosinergic axis regulates locomotion of immune cells. ${ }^{29,46}$ The inference in the CLL context would be that leukemic cells are attracted to LNs by CXCL12 that provides a long-range signal, whereas local ADO induces a short-range stop signal ${ }^{29}$ that keeps cells in a growthfavorable environment. A2A effects on chemotaxis are believed to rely mainly on surface down-regulation of chemokine receptors ${ }^{30,47}$ and cAMP-mediated chemokine receptor desensitization. ${ }^{48}$ In line with these observations, CXCR4 surface expression levels were markedly down-regulated in $\mathrm{CD} 73^{+}$patients.

We then asked whether these findings might be relevant to the course of the disease by testing the influence of extracellular ADO on the effects mediated by drugs. The role of ADO on apoptosis is controversial. Some studies show that it reduces viability, arrests the cell cycle, and induces apoptosis, ${ }^{49}$ whereas other studies support a cytoprotective role. ${ }^{50,51}$ A plausible explanation for these contrasting results is related to the expression of different types of ADO receptors that could activate or block the synthesis of intracellular cAMP and by the subsequent relative increase or decrease in cAMP concentrations. Our results document that extracellular ADO has potent effects in protecting CLL cells from spontaneous or etoposide-induced apoptosis. These effects are apparent in a specific dose range $(30-60 \mu \mathrm{M})$, compatible with the concentrations measured in HPLC studies and in line with evidence favoring a dose-specific effect of ADO ${ }^{27}$ The observation that an A2A receptor agonist delivers comparable effects indicates that $\mathrm{ADO}$ functions by activating the $\mathrm{A} 2 \mathrm{~A}$ receptor. These findings are in keeping with data showing protective effects mediated by cAMP through the activation of the NF- $\mathrm{B}$ pathway, in turn impairing the p53-dependent apoptotic process. ${ }^{52}$ Consistently, exposure of CLL cells to ADO in the presence of etoposide modulates the expression of the p53-dependent genes Mcl-1 and BAX, ultimately decreasing activation of caspase- 3 .
When CLL cells are treated with fludarabine, a mainstay in CLL therapy, a repeated supply of ADO induces complete protection from apoptosis. This effect is not fully recapitulated by the A2A agonist, suggesting that in this setting ADO activates both A2Adependent and -independent protective mechanisms. However, because ADO and fludarabine are remarkably similar, it is possible that they compete for nucleoside transporters that mediate entrance to the cell ${ }^{53}$ and for intracellular effectors. If this is true, then excess amount of extracellular ADO would limit fludarabine accessibility to its final targets, one of the proposed mechanisms behind fludarabine resistance. ${ }^{54}$

Together, these results suggest that targeting the adenosinergic axis might have considerable therapeutic impact in the control of CLL progression and/or in potentiating the effects of chemotherapy. One manner to achieve this goal could be via blocking of CD73, an approach proposed for solid tumors. ${ }^{20}$ This may, however, be detrimental in the CLL context of chemotherapy, considering that soluble CD73 seems to be one of the main phosphatases that transform fludarabine phosphate (Fludara) into the active drug. ${ }^{53}$ Although other serum phosphatases may compensate for the loss of CD73, this specific issue should be considered in patients receiving chemotherapy with fludarabine. Alternatively, the use of antagonists of the A2A receptor that could limit the increase in cytoplasmic cAMP levels associated with antiapoptosis and chemoresistance may be envisioned. There are several specific antagonists of the A2A receptor, one of which, Preladenant, has been in clinical trials for Parkinson's disease. ${ }^{55}$ The drug can be administered orally and has been generally well tolerated.

In conclusion, the data presented in this work highlight the existence of local microenvironmental conditions that favor accumulation of extracellular ADO specifically in the proliferation centers of CLL LNs. The results identify an autocrine signaling loop that contributes to creating a "protective halo" around the proliferating elements of the leukemia, providing partial protection from the action of chemotherapy. It remains to be determined whether there is also a paracrine component that modulates communications between ADO-producing CLL cells and the surrounding nonneoplastic cellular component, as was shown in solid tumor models. ${ }^{56}$ Among follicular dendritic cells, endothelial cells, and T lymphocytes, the latter population is perhaps the first candidate to be tested in a paracrine hypothesis. Preliminary data indicate that $\mathrm{T}$ cells purified from CLL patients express significantly higher levels of the A2A receptor compared with the same population purified from age- and sex-matched donors (S. S., S. D., unpublished observation). Future work will determine whether ADO production also might be relevant in T-cell homeostasis and in further shaping T-cell responses, favoring the production of T-helper 2-type cytokines that are essential for CLL growth and angiogenesis.

\section{Acknowledgments}

This work was supported by Associazione Italiana Ricerca Cancro (IG 8590 and Special Program Molecular Clinical Oncology "5 per Mille" 9980, 2010/15) and the Italian Ministries of Health (Bando Giovani Ricercatori 2008) and Education (Bando FIRB Giovani 2008 and Bando PRIN 2009). The Fondazione Internazionale Ricerca in Medicina Sperimentale (FIRMS) provided valuable administrative assistance. 


\section{Authorship}

Contribution: S.S. designed the study, performed experiments, and analyzed data; A.L.H. designed and performed HPLC experiments; T.V. performed biochemical experiments; D.B. performed chemotaxis experiments; D.R. performed statistical analyses; L.L., G.D., and M.C. provided patient samples and relevant clinical information; C.T. assisted in the set up of the histologic stainings; G.I. provided LN sections, scored slides, and contributed to data interpretation; G.G. provided patient samples and contributed to data interpretation; S.C.R. contributed to data interpretation; F.M. contributed to study design, data interpretation, and drafting of the manuscript; and S.D. designed the study, analyzed and interpreted data, and wrote the paper.

Conflict-of-interest disclosure: The authors declare no competing financial interests.

Correspondence: Silvia Deaglio, University of Turin School of Medicine and Human Genetics Foundation (HuGeF), via Nizza 52, 10126 Torino, Italy; e-mail: silvia.deaglio@ unito.it.

\section{References}

1. Dighiero G, Hamblin TJ. Chronic lymphocytic leukaemia. Lancet. 2008;371(9617):1017-1029.

2. Chiorazzi N. Cell proliferation and death: forgotten features of chronic lymphocytic leukemia B cells. Best Pract Res Clin Haematol. 2007; 20(3):399-413.

3. Chiorazzi N, Ferrarini M. Cellular origin(s) of chronic lymphocytic leukemia: cautionary notes and additional considerations and possibilities. Blood. 2011;117(6):1781-1791.

4. Caligaris-Cappio F, Ghia P. Novel insights in chronic lymphocytic leukemia: are we getting closer to understanding the pathogenesis of the disease? J Clin Oncol. 2008;26(27):4497-4503.

5. Soma LA, Craig FE, Swerdlow SH. The proliferation center microenvironment and prognostic markers in chronic lymphocytic leukemia/small lymphocytic lymphoma. Hum Pathol. 2006;37(2): 152-159.

6. Patten PE, Buggins AG, Richards J, et al. CD38 expression in chronic lymphocytic leukemia is regulated by the tumor microenvironment. Blood. 2008;111(10):5173-5181.

7. Wickremasinghe RG, Ganeshaguru K, Jones DT, et al. Autologous plasma activates Akt/protein kinase $B$ and enhances basal survival and resistance to DNA damage-induced apoptosis in Bchronic lymphocytic leukaemia cells. Br J Haematol. 2001;114(3):608-615.

8. Seiffert M, Schulz A, Ohl S, Dohner H, Stilgenbauer S, Lichter P. Soluble CD14 is a novel monocyte-derived survival factor for chronic lymphocytic leukemia cells, which is induced by CLL cells in vitro and present at abnormally high levels in vivo. Blood. 2010;116(20): 4223-4230.

9. Di Virgilio F, Boeynaems JM, Robson SC. Extracellular nucleotides as negative modulators of immunity. Curr Opin Pharmacol. 2009;9(4):507513.

10. Burnstock G. Unresolved issues and controversies in purinergic signalling. $J$ Physiol (London). 2008;586(14):3307-3312.

11. Burnstock G, Verkhratsky A. Evolutionary origins of the purinergic signalling system. Acta Physiol. 2009;195(4):415-447.

12. Resta R, Yamashita Y, Thompson LF. Ectoenzyme and signaling functions of lymphocyte CD73. Immunol Rev. 1998;161:95-109.

13. Haskó G, Cronstein BN. Adenosine: an endogenous regulator of innate immunity. Trends Immu nol. 2004;25(1):33-39.

14. Sitkovsky MV, Ohta A. The 'danger' sensors that STOP the immune response: the A2 adenosine receptors? Trends Immunol. 2005;26(6):299-304.

15. Deaglio S, Dwyer KM, Gao W, et al. Adenosine generation catalyzed by CD39 and CD73 expressed on regulatory $T$ cells mediates immune suppression. J Exp Med. 2007;204(6):1257-1265.

16. Borsellino $G$, Kleinewietfeld M, Di Mitri D, et al. Expression of ectonucleotidase CD39 by Foxp3+ Treg cells: hydrolysis of extracellular ATP and immune suppression. Blood. 2007;110(4):12251232.
17. Ernst PB, Garrison JC, Thompson LF. Much ado about adenosine: adenosine synthesis and function in regulatory T cell biology. J Immunol. 2010; 185(4):1993-1998

18. Pellegatti P, Raffaghello L, Bianchi G, Piccardi F, Pistoia V, Di Virgilio F. Increased level of extracellular ATP at tumor sites: in vivo imaging with plasma membrane luciferase. PLoS One. 2008; 3(7):e2599.

19. Ohta A, Gorelik E, Prasad SJ, et al. A2A adenosine receptor protects tumors from antitumor T cells. Proc Natl Acad Sci U S A. 2006;103(35): 13132-13137.

20. Stagg J, Smyth MJ. Extracellular adenosine triphosphate and adenosine in cancer. Oncogene. 2010;29(39):5346-5358

21. Mikhailov A, Sokolovskaya A, Yegutkin GG, et al. CD73 participates in cellular multiresistance program and protects against TRAIL-induced apoptosis. J Immunol. 2008;181(1):464-475.

22. Stagg J, Divisekera U, McLaughlin N, et al. AntiCD73 antibody therapy inhibits breast tumor growth and metastasis. Proc Natl Acad Sci U S A 2010;107(4):1547-1552.

23. Wang L, Fan J, Thompson LF, et al. CD73 has distinct roles in nonhematopoietic and hematopoietic cells to promote tumor growth in mice. J Clin Invest. 2011;121(6):2371-2382.

24. Audrito V, Vaisitti T, Rossi D, et al. Nicotinamide blocks proliferation and induces apoptosis of chronic lymphocytic leukemia cells through activation of the p53/miR-34a/SIRT1 tumor suppressor network. Cancer Res. 2011;71(13):44734483.

25. Vaisitti T, Aydin S, Rossi D, et al. CD38 increases CXCL12-mediated signals and homing of chronic lymphocytic leukemia cells. Leukemia. 2010;24: 958-969.

26. Marcus AJ, Broekman MJ, Drosopoulos JH, et al The endothelial cell ecto-ADPase responsible for inhibition of platelet function is CD39. J Clin Invest. 1997;99(6):1351-1360.

27. Haskó G, Linden J, Cronstein B, Pacher P. Adenosine receptors: therapeutic aspects for inflammatory and immune diseases. Nat Rev Drug Discov. 2008;7(9):759-770.

28. Burger JA, Kipps TJ. CXCR4: a key receptor in the crosstalk between tumor cells and their microenvironment. Blood. 2006;107(5):1761-1767.

29. Junger WG. Immune cell regulation by autocrine purinergic signalling. Nat Rev Immunol. 2011 11(3):201-212.

30. By Y, Durand-Gorde JM, Condo J, et al. Monoclonal antibody-assisted stimulation of adenosine A2A receptors induces simultaneous downregulation of CXCR4 and CCR5 on CD4+ T-cells. Hum Immunol. 2010;71(11):1073-1076.

31. Naderi EH, Findley HW, Ruud E, Blomhoff HK, Naderi S. Activation of CAMP signaling inhibits DNA damage-induced apoptosis in BCP-ALL cells through abrogation of p53 accumulation. Blood. 2009;114(3):608-618.

32. Damle RN, Ghiotto F, Valetto A, et al. B-cell chronic lymphocytic leukemia cells express a sur- face membrane phenotype of activated, antigen experienced B lymphocytes. Blood. 2002;99(11) 4087-4093.

33. Rosi F, Tabucchi A, Carlucci F, et al. 5'-nucleotidase activity in lymphocytes from patients affected by Bcell chronic lymphocytic leukemia. Clin Biochem. 1998;31(4):269-272.

34. Pulte D, Furman RR, Broekman MJ, et al. CD39 expression on $T$ lymphocytes correlates with severity of disease in patients with chronic lymphocytic leukemia. Clin Lymphoma Myeloma Leuk. 2011;11(4):367-372.

35. Malavasi F, Deaglio S, Damle R, Cutrona G Ferrarini M, Chiorazzi N. CD38 and chronic lymphocytic leukemia: a decade later. Blood. 2011; 118(13):3470-3478.

36. Crespo M, Bosch F, Villamor N, et al. ZAP-70 expression as a surrogate for immunoglobulinvariable-region mutations in chronic lymphocytic leukemia. N Engl J Med. 2003;348(18):17641775.

37. Richardson SJ, Matthews C, Catherwood MA, et al. ZAP-70 expression is associated with enhanced ability to respond to migratory and survival signals in B-cell chronic lymphocytic leukemia (B-CLL). Blood. 2006;107(9):3584-3592.

38. Takedachi M, Qu D, Ebisuno Y, et al. CD73generated adenosine restricts lymphocyte migration into draining lymph nodes. J Immunol. 2008; 180(9):6288-6296.

39. Goepfert C, Sundberg C, Sevigny J, et al. Disordered cellular migration and angiogenesis in cd39-null mice. Circulation. 2001;104(25):31093115.

40. Blay J, White TD, Hoskin DW. The extracellular fluid of solid carcinomas contains immunosuppressive concentrations of adenosine. Cancer Res. 1997;57(13):2602-2605.

41. Borrione P, Peola S, Mariani S, et al. CD38 stimulation lowers the activation threshold and enhances the alloreactivity of cord blood T cells by activating the phosphatidylinositol 3-kinase path way and inducing CD73 expression. J Immunol. 1999;162(10):6238-6246.

42. Clark RR, Soutar DS. Lymph node metastases from auricular squamous cell carcinoma. A systematic review and meta-analysis. J Plast Reconstr Aesthet Surg. 2008;61(10):1140-1147.

43. Hilchey SP, Kobie JJ, Cochran MR, et al. Human follicular lymphoma CD39+-infiltrating T cells contribute to adenosine-mediated T cell hyporesponsiveness. J Immunol. 2009;183(10):61576166

44. Devereux S. Two-faced T cells in CLL. Blood 2011;117(20):5273-5274.

45. Salmi M, Jalkanen S. Cell-surface enzymes in control of leukocyte trafficking. Nat Rev Immunol. 2005;5(10):760-771.

46. Färber K, Markworth S, Pannasch U, et al. The ectonucleotidase cd39/ENTPDase1 modulates purinergic-mediated microglial migration. Glia. 2008;56(3):331-341.

47. Williams $A J$, Cronstein $B N$. The effect of $A(2 A)$ Adenosine receptor activation on C-C Chemokine 
From www.bloodjournal.org by guest on October 8, 2014. For personal use only.

receptor 7 expression in human THP1 macrophages during inflammation [published online ahead of print July 8, 2011]. Inflammation. doi: 10.1007/s10753-011-9353-1.

48. Zhang $\mathrm{N}$, Yang D, Dong $\mathrm{H}$, et al. Adenosine A2a receptors induce heterologous desensitization of chemokine receptors. Blood. 2006;108(1):38-44.

49. Jacobson KA, Hoffmann C, Cattabeni F, Abbracchio MP. Adenosine-induced cell death: evidence for receptor-mediated signalling. Apoptosis. 1999;4(3):197-211.

50. Apasov S, Chen JF, Smith P, Sitkovsky M. A(2A) receptor dependent and $A(2 A)$ receptor independent effects of extracellular adenosine on murin thymocytes in conditions of adenosine deaminase deficiency. Blood. 2000;95(12):3859-3867.

51. Himer L, Csoka B, Selmeczy Z, et al. Adenosine $\mathrm{A} 2 \mathrm{~A}$ receptor activation protects $\mathrm{CD} 4+\mathrm{T}$ lymphocytes against activation-induced cell death. FASEB J. 2010;24(8):2631-2640.

52. Naderi A, Chia KM, Liu J. Synergy between inhibitors of androgen receptor and MEK has therapeutic implications in estrogen receptor-negative breast cancer. Breast Cancer Res. 2011;13(2): R36.

53. Mackey JR, Galmarini CM, Graham KA, et al. Quantitative analysis of nucleoside transporter and metabolism gene expression in chronic lymphocytic leukemia (CLL): identification of fludara- bine-sensitive and -insensitive populations. Blood. 2005;105(2):767-774.

54. Galmarini CM, Mackey JR, Dumontet C. Nucleoside analogues: mechanisms of drug resistance and reversal strategies. Leukemia. 2001;15(6): 875-890.

55. Hauser RA, Cantillon M, Pourcher E, et al. Preladenant in patients with Parkinson's disease and motor fluctuations: a phase 2, double-blind, randomised trial. Lancet Neurol. 2011;10(3):221 229.

56. Jin D, Fan J, Wang L, et al. CD73 on tumor cells impairs antitumor T-cell responses: a novel mechanism of tumor-induced immune suppression. Cancer Res. 2010;70(6):2245-2255. 